\title{
Settlement cues in an Atlantic coast population of the ghost shrimp Callichirus major (Crustacea: Decapoda: Thalassinidea)
}

\author{
K. M. Strasser*, D. L. Felder \\ Department of Biology, University of Southwestern Louisiana, PO Box 42451, Lafayette, Louisiana 70504-2451, USA
}

\begin{abstract}
Larvae of Callichirus major (Say) were first given stimuli upon reaching the last zoeal stage (ZIV), decapodid stage (D), or first juvenile stage (J1). Animals were provided with sand and unconditioned water, water conditioned by previous exposure to adults (adult-conditioned water = AW), or both stimuli to determine if these factors could serve as settlement cues. ZIV was found to be important in the settlement process. Animals that received sand and AW at ZIV burrowed more than those that received stimuli at $D$. Whereas larvae of the Atlantic population delayed molting to $D$ in the absence of stimuli, they did so differently than previously found in a Gulf of Mexico population. In the Gulf population, duration of ZIV decreased in the presence of AW. In contrast, duration of ZIV in the Atlantic population increased significantly in the presence of stimuli at this stage, which led larvae to molt directly from ZIV to D. The percentage of animals molting directly from ZIV to D (bypassing the fifth zoeal stage) was significantly higher in animals that received stimuli at ZIV than it was in animals that did not receive stimuli at this stage. When each stimulus was offered alone results were not equivalent to those when stimuli were offered in combination. The Atlantic population required presence of both stimuli at ZIV for settlement, while exposure of ZIV larvae to sand alone was sufficient to induce settlement of postlarvae in the Gulf population.
\end{abstract}

KEY WORDS: Settlement cues · Sediment $\cdot$ Stimuli $\cdot$ Adult-conditioned water $\cdot$ Zoea

\section{INTRODUCTION}

Studies of settlement in decapod crustaceans have focused primarily on the first postlarval stage. This stage may be termed generally the decapodid (Felder et al. 1985) with synonyms megalopa, glaucothoe, and puerulus applied to selected taxa. The decapodid stage (D) is thought to make the transition from the pelagic existence to the benthic one. Since this stage is usually considered to be the settlement stage (Jensen 1991), it is also the stage assumed to be receptive to putative settlement cues. Decapod larvae typically hatch as a swimming zoea and may pass through several zoeal stages before they reach the decapodid. The zoeal stages are usually the pelagic phase of development,

\footnotetext{
- Present address: Dept. Biology, University of Tampa, Tampa, Florida 33606-1490, USA.

E-mail: kstrasser@alpha.utampa.edu
}

and thus often ignored in experiments on settlement stimuli. A notable exception was found in the mole crab Emerita talpoida (Say), which extends the duration of the later zoeal stages in the absence of sand (Harvey 1993). This finding suggests that the zoeal stages may be receptive to settlement stimuli.

To test the hypothesis that decapod postlarvae respond to settlement cues, several studies have demonstrated a delay in molting to $\mathrm{J} 1$ (Cobb 1968, Christy 1989, Harms 1992, Harvey 1992a, b, Harvey \& Colasurdo 1993, Harvey 1996, Weber \& Epifanio 1996, O'Connor 1997, Gebauer et al. 1998). This is typically done by comparing the duration of the decapodid stage in the presence and absence of stimuli. If an animal needs a specific stimulus to settle, it should delay activities that lead to settlement in the absence of the cue. Whereas settlement and metamorphosis are tightly linked in some animals, research has shown that these events may sometimes be relatively independent in 
marine crustaceans. The barnacle Balanus balanoides (L.) will molt $24 \mathrm{~h}$ after settlement (Knight-Jones 1953), while in the porcelain crabs Petrolisthes eriomerus Stimpson and $P$. cinctipes (Randall) this period can last a week (Jensen 1989). In our paper, settlement and metamorphosis will be treated as separate events.

Two populations of Callichirus major (Say), one on the coast of Louisiana (Gulf of Mexico population) and one on the East coast of Florida (Atlantic population), have been shown to be genetically distinct (Staton \& Felder 1995). Whereas individuals in both populations are gregarious, they have differential intertidal distributions (Felder \& Griffis 1994). Callichirus major (Atlantic) has been found to inhabit middle to high intertidal quartzite, sandy substrates on ocean-facing beaches and inlet margins of barrier islands. In the Gulf of Mexico, C. major appears to prefer low intertidal to subtidal sandy substrates on the bay side and inlets of barrier islands. If adult distributions are shaped by settlement, it can be inferred that some cue triggers larvae to settle in the adult habitat and that they increase their survival by doing so.

Larvae from the Gulf of Mexico population of Callichirus major have been shown to respond to sand (a contact cue) and adult-conditioned water (a waterborne cue) when offered at the fourth zoeal stage (ZIV) (Strasser \& Felder 1998). Larvae delayed settlement in the absence of sand at ZIV, and delayed molting to $D$ in the absence of adult-conditioned water at ZIV. Morphological differences in the larvae (Strasser \& Felder 1999) and genetic differences (Staton \& Felder 1995) between these 2 populations of $C$. major prohibit the use of generalizations for this 'species'. Experiments on the response of C. major (Atlantic) to settlement cues have been conducted to determine if the process of settlement is consistent between populations of this species. The following hypotheses were tested in this study: (1) presence of stimuli at ZIV decreases the duration of this stage; (2) duration of $D$ is not extended in the absence of stimuli at ZIV or $D_{i}$ (3) presence of stimuli at ZIV triggers the settlement of decapodids.

\section{MATERIALS AND METHODS}

Experimental protocol. Ovigerous females were collected from a sand flat on the north side of Sebastian Inlet, Florida $\left(27^{\circ} 51.7^{\prime} \mathrm{N}, 80^{\circ} 26.8^{\prime} \mathrm{W}\right)$ in May, June, and July, 1997 , by extracting burrowed animals with a yabby pump (see Felder 1978). Protocols were in general as previously described for experiments with Gulf of Mexico populations (Strasser \& Felder 1998). Adult females were maintained in $20 \mathrm{~cm}$ diameter finger bowls at 35 ppt salinity with daily water changes until eggs hatched. Seawater was taken from well offshore
Florida, filtered through a $30 \mu \mathrm{m}$ screen, and aerated before use. ZI (first zoeal stage) larvae were moved to individual compartments of a plastic tray upon hatching and maintained at $27^{\circ} \mathrm{C}$, in filtered seawater (35 ppt salinity), and on a $12 \mathrm{~h}$ light:12 h dark cycle. Each day larvae were moved to containers with new seawater, fed freshly hatched Artemia nauplii (Great Salt Lake), and examined to assess their stage of development. Each experimental treatment began with 40 ZI larvae which were reared without stimuli through the third zoeal stage (ZIII). All larvae remained isolated for the duration of each experiment.

To determine if larvae of Callichirus major from the western Atlantic responded to settlement cues, 2 experimental protocols were followed (Fig. 1). Expt 1 was conducted to examine the combined effect of sand and adult-conditioned water when offered at different stages of development. Adult-conditioned water was prepared by holding adult male and female specimens of C. major (carapace length $\sim 12 \mathrm{~mm}$ ) in aerated water at a ratio of 1 ind. $\mathrm{l}^{-1}$ for at least $24 \mathrm{~h}$. Sand was taken from the adult habitat, sieved through a $0.6 \mathrm{~mm}$ mesh screen, rinsed with deionized water, dried, and then rinsed with 35 ppt salinity seawater before it was used in experiments. A layer of sand $\sim 8 \mathrm{~mm}$ deep was used as a stimulus.

In Expt 1. animals were first provided with stimuli upon reaching ZIV (the fourth zoeal stage), D (the de-

\begin{tabular}{llllllll} 
ZI & Z II & Z III & Z IV & Z V & D & J1 & J2 \\
\hline
\end{tabular}

Experiment 1

No stimulus

Experiment 2

Nostimulus

Fig. 1 Callichirus major. Summary of experimental treatments conducted with developmental stages from the Atlantic coast population of Florida (USA). In Expt 1 animals first received sand and adult-conditioned water (AW) at the fourth zoeal stage (ZIV), the decapodid stage (D), or the first juvenile stage (J1); treatments were repeated twice fully (Expts $1 \mathrm{~A}$, and $1 \mathrm{~B}$ ) and once partially (1C). In Expt 2, animals received sand and AW, AW only, sand only, or no stimulus at ZIV, and all animals received sand and $A W$ after the molt to $D_{i}$ treatments were repeated 3 times (Expts $2 \mathrm{~A}, 2 \mathrm{~B}$, and $2 \mathrm{C}$ ). $\mathrm{A}$ thin line designates stages that did not receive stimuli, while a thick line designates stages that received sand and/or AW 
capodid stage), or $\mathrm{J} 1$ (the first juvenile stage). Once offered, a stimulus was maintained until observations were terminated at the time that each animal reached the second day of $\mathrm{J} 2$ (the second juvenile stage). Observations on the burrowing behavior of juveniles were made to determine if effects of delayed stimuli (decreased burrowing and molting in the sand) persisted after postlarvae molted from D to J1. This experiment was conducted twice (Expts $1 \mathrm{~A}$ and $1 \mathrm{~B}$ ) to assure that observations were not unique to a single larval clutch. A third experiment (1C) followed the treatment proto$\mathrm{col}$ of $1 \mathrm{~A}$ and $1 \mathrm{~B}$. However, because of time constraints, experimentation was terminated after animals molted from ZIV to ZV (the fifth zoeal stage) or D. Data from Expt $1 \mathrm{C}$ was used only to analyze the number of stages.

Expt 2 was conducted to separate the effects of sand from those of adult-conditioned water when offered at ZIV. Animals were offered sand and adult-conditioned water, adult-conditioned water only, sand only, or no stimulus upon reaching ZIV. All animals received sand and adult-conditioned water after the molt to the decapodid stage and observations were terminated when each animal reached the second day of $\mathrm{J} 1$. This experiment was conducted 3 times, each time with larvae from a different parental female (2A, 2B, 2C).

In all experiments, daily observations were made before the animal was moved to a container with new water (and sand if applicable). Animal positions were recorded as either burrowed or not burrowed for each day after the molt to $\mathrm{D}$. To be classified as burrowed, the animal must have been either burrowed in the sand and/or have constructed one or more cemented burrow openings. Animals that were observed to have manipulated the sand, but without any form of burrow construction, were classified as not burrowed. When animals molted to $\mathrm{J} 1$ or $\mathrm{J} 2$, position of the exuvium was recorded as being on top of the sand or as within the sand. In cases where exuviae were not found, those animals were excluded from the molt-location analyses.

Analysis of data. To determine if larvae delayed molting in the absence of stimuli, durations of ZIV and $D$ were compared between treatments. In Expts $1 \mathrm{~A}$ and 1B, a 1-factor ANOVA (Type III sums of squares) was used to test the effect of stimuli at different stages (ZIV, $\mathrm{D}$ or J1) on the durations of ZIV and D. The TukeyKramer and Tukey compromise post hoc tests were used to make individual comparisons. In Expts 2A, 2B, and $2 \mathrm{C}$, a 2-factor ANOVA was used to separate the effects of sand from those of adult-conditioned water on the durations of ZIV and D. Only animals that reached $\mathrm{J} 1$ were included in the analysis of stage duration.

Number of zoeal stages (4 vs 5) that each animal passed through was also compared between treatments. The percentage of larvae in each treatment that molted directly from ZIV to D, as opposed to first passing through a fifth zoeal stage, was compared by Fisher's exact-test (tests 2-tailed, alpha $=0.05$ ). To determine if the duration of ZIV varied depending on the stage larvae molted to (to ZV or D), Student's $t$-test was used to compare mean durations of ZIV in larvae that molted directly from ZIV to D or from ZIV to ZV in each experiment. All animals that survived beyond ZIV were included in this analysis.

To determine the effect of stimuli on settlement of postlarvae, observations on burrowing activity of decapodids and juveniles were compared between treatments. First, the percentage of D and J1 that each animal spent burrowed (excluding Day 1) was calculated. The first day of the decapodid stage was not included since animals in treatments first given sand at $D$ did not have sand to burrow in on their first day as decapodids. In Expts 1A and 1B, Student's t-test was used to compare the mean percentages of D spent burrowed between animals that received sand and adultconditioned water at ZIV, as opposed to D. To determine if the effect of delaying stimuli on settlement of postlarvae persisted to $\mathrm{J} 1$, burrowing activity of juveniles was also compared between treatments. A 1 factor ANOVA (Type III sums of squares) was used to compare the effect of receiving stimuli at different stages (at ZIV, D, or J1) on the mean percentage of J1 spent burrowed. In Expts 2A, 2B, and 2C a 2-factor ANOVA (Type III sums of squares) was used to separate the effects of sand from those of adult-conditioned water on the percentage of the decapodid stage spent burrowed.

Location of molt exuviae was used to indicate position of animals at molting (from D to J1 and J1 to J2). The percentages of molt exuviae found in the sand (= molted while burrowed) were compared between treatments by Fisher's exact-test in each experiment. For observations on decapodid burrowing and location of $\mathrm{D}$ exuviae (molt from $\mathrm{D}$ to $\mathrm{J} 1$ ), only normal (not deformed at $D$ ) animals that survived the molt to J1 were included in the analysis. For analysis of burrowing at $\mathrm{J} 1$ and location of exuviae from the molt of $\mathrm{J} 1$ to $\mathrm{J} 2$ only animals that were not malformed at $\mathrm{J} 1$ and that survived to $\mathrm{J} 2$ were included.

Data were analyzed with Excel $5.0^{\circledR}$, Statview $4.5^{\circledR}$, Super ANOVA $1.11^{\oplus}$, and NCSS $6.0^{\oplus}$. In Student's $t$-tests and ANOVA tests with percentages, data were arcsine square-root transformed before comparisons were made. The $\mathrm{p}$-values reported are from tests made with transformed values. However, differences thusly reported as significant were also found to be significant $(p<0.05)$ when untransformed data were analyzed. The Type III sums of squares ANOVA was used because treatments often differed in number of observations. 


\section{RESULTS}

\section{Rate of development}

There was no evidence of delayed molting from $D$ to $\mathrm{J} 1$ in the absence of stimuli at ZIV or D. In all experiments duration of $D$ was not shorter in animals that received stimuli at ZIV, as opposed to D, and was actually longer in some experiments (Table 1). Timing of the stimulus (at ZIV, D, or J1) was found to have a significant effect on the duration of $D$ in Expts $1 \mathrm{~A}$ and $1 \mathrm{~B}$. However, in both experiments duration of $\mathrm{D}$ was found to be longer in treatments that received sand and adult-conditioned water at ZIV, instead of at D or J1. Duration of $\mathrm{D}$ did not differ significantly between treatments in Expts $2 \mathrm{~A}$ and $2 \mathrm{C}$. However, in Expt $2 \mathrm{~B}$, effects of sand, adult-conditioned water, and the interaction between stimuli were significant with a 2 -factor ANOVA. Once again, this was most likely because the duration of $D$ was longer in animals that received both sand and adult-conditioned water at ZIV than in those that received one or no stimulus at ZIV. The duration of $D$ was similar in all experiments.

In all experiments, the mean duration of ZIV was longer in treatments that received sand and adultconditioned water at ZIV than it was in those that received one or no stimulus at this stage (Table 1 ). In Expts $1 \mathrm{~A}$ and $1 \mathrm{~B}$, the difference between animals that received sand and adult-conditioned water, as opposed to no stimulus at ZIV, was not significant. With a 2-factor-ANOVA, adult-conditioned water had a significant effect on the duration of ZIV in Expts $2 \mathrm{~A}$, $2 \mathrm{~B}$, and $2 \mathrm{C}$, while the effects of sand and the interaction of stimuli were not significant. However, both adult-conditioned water and sand increased the duration of ZIV.

\section{Number of zoeal stages}

In Expts $1 \mathrm{~B}, 1 \mathrm{C}, 2 \mathrm{~A}, 2 \mathrm{~B}$, and 2C, significantly more animals molted directly from ZIV to D (bypassing ZV) when they received sand and adult-conditioned water at ZIV as opposed to no stimulus at ZIV (Table 2). All larvae in Expt $1 \mathrm{~A}$ bypassed $\mathrm{ZV}$. In Expts $2 \mathrm{~A}, 2 \mathrm{~B}$ and $2 C$, animals that received adult-conditioned water only or sand only at ZIV more commonly molted directly from ZIV to $D$ (no $\mathrm{ZV}$ ) than did those that received no stimulus at ZIV. However, neither stimulus alone decreased the number of zoeal stages as consistently as did both sand and adult-conditioned water in combination.

Table 1. Callichirus major. Mean durations in days ( $\pm 95 \%$ CI) of the fourth zoeal stage (ZIV) and decapodid stage (D) for each experimental treatment. Animals received sand and/or adult-conditioned water (AW) at ZIV, D, or the first juvenile stage (J1). Only animals that successfully molted to $\mathrm{J} 1$ were included in the analysis. Effect of $\mathrm{AW}$ was significant in Expts $2 \mathrm{~A}\left(F_{1,95}=4.98\right.$, $\mathrm{p}=0.028), 2 \mathrm{~B}\left(F_{1,118}=4.72, \mathrm{p}=0.032\right)$, and $2 \mathrm{C}\left(F_{1,134}=11.05, \mathrm{p}=0.0011\right)$, effects of sand and interaction between stimuli were not significant (2-factor ANOVA); "treatment means significantly different in Expts $1 \mathrm{~A}\left(F_{2,106}=23.57, \mathrm{p}=0.0001\right)$ and $1 \mathrm{~B}\left(F_{2,81}=\right.$ $3.51, p=0.034)$ (1-factor ANOVA); treatments with same superscript letter did not differ significantly in both Tukey-Kramer and Tukey compromise post hoc tests (alpha $=0.05)$. $\cdots$ Effects of sand $\left(F_{1,1+8}=6.33, \mathrm{p}=0.013\right)$, AW $\left(F_{1,118}=11.44, \mathrm{p}=0.001\right)$ and interaction between stimuli $\left(F_{1,118}=8.23, \mathrm{p}=0.0049\right)$ were significant ( 2 -factor ANOVA)

\begin{tabular}{|c|c|c|c|}
\hline Duration of ZIV & Expt $1 \mathrm{~A}$ & Expt 1B & \\
\hline Sand and AW at ZIV & $3.82( \pm 0.181) n=34$ & $3.85( \pm 0.125) \mathrm{n}=34$ & \\
\hline Sand and AW at D & $3.72( \pm 0.156) \mathrm{n}=36$ & $3.82( \pm 0.175) n=22$ & \\
\hline \multirow[t]{2}{*}{ Sand and $A W$ at $J 1$} & $3.67( \pm 0.154) n=39$ & $3.61( \pm 0.220) n=28$ & \\
\hline & $\operatorname{Expt} 2 \mathrm{~A}^{\circ}$ & Expt $2 \mathrm{~B}^{\circ}$ & Expt $2 \mathrm{C}^{\cdot}$ \\
\hline Sand and AW & $3.20( \pm 0.245) \mathrm{n}=20$ & $3.50( \pm 0.273) n=30$ & $3.66( \pm 0.220) n=35$ \\
\hline AW at ZIV & $3.12( \pm 0.143) n=24$ & $3.19( \pm 0.213) \mathrm{n}=32$ & $3.53( \pm 0.206) n=36^{\cdots}$ \\
\hline Sand at ZIV & $3.04( \pm 0.139) n=26$ & $3.15( \pm 0.179) n=33$ & $3.29( \pm 0.157) \mathrm{n}=35$ \\
\hline No stimulus at ZIV & $2.93( \pm 0.141) n=29$ & $3.07( \pm 0.188) n=27$ & $3.25( \pm 0.205) n=35$ \\
\hline Duration of $\mathrm{D}$ & Expt $1 \mathrm{~A} \cdots$ & Expt $1 B \cdots$ & \\
\hline Sand and AW at ZIV & $4.06( \pm 0.083) \mathrm{n}=34^{\mathrm{a}}$ & $3.53( \pm 0.177) \mathrm{n}=34^{4}$ & \\
\hline Sand and AW at D & $3.72( \pm 0.174) n=36^{b}$ & $3.18( \pm 0.222) n=22^{a}$ & \\
\hline Sand and AW at J1 & $3.36( \pm 0.158) n=39^{c}$ & $3.25( \pm 0.227) n=28^{a}$ & \\
\hline & Expt $2 \mathrm{~A}$ & Expt 2B $\cdots$ & Expt 2C \\
\hline Sand and AW at ZIV & $3.35( \pm 0.229) n=20$ & $3.60( \pm 0.186) n=30$ & $3.26( \pm 0.152) n=35$ \\
\hline AW at ZIV & $3.33( \pm 0.204) \mathrm{n}=24$ & $3.19( \pm 0.142) n=32$ & $3.42( \pm 0.169) n=36$ \\
\hline Sand at ZIV & $3.38( \pm 0.257) \mathrm{n}=26$ & $3.12( \pm 0.118) \mathrm{n}=33$ & $3.26( \pm 0.152) n=35$ \\
\hline No stimulus at ZIV & $3.52( \pm 0.281) n=29$ & $3.15( \pm 0.181) \mathrm{n}=27$ & $3.16( \pm 0.186) n=32$ \\
\hline
\end{tabular}


Table 2. Callichirus major. Percentage of larvae that molted directly from the fourth zoeal stage (ZIV) to the decapodid stage (D) as opposed to first passing through a fifth zoeal stage. The percentage of decapodids that were deformed in each treatment is also given. In Expt 1 , animals received sand and adult-conditioned water (AW) at ZIV or D. In Expt 2, animals received sand and AW, AW only, sand only, or no stimulus at ZIV and all animals received sand and AW at D. Different lower case letters represent a significant difference between treatments by Fisher's exact-test within an experiment (all tests 2 tailed, alpha $=0.05$ )

\begin{tabular}{|c|c|c|c|c|}
\hline Expt & Treatment & $\begin{array}{l}\text { No. that molted } \\
\text { from ZIV }\end{array}$ & $\begin{array}{l}\% \text { molted from } \\
\text { ZIV to D }\end{array}$ & $\begin{array}{l}\% \text { of decapodids } \\
\text { that were deformed }\end{array}$ \\
\hline \multirow[t]{3}{*}{$1 \mathrm{~A}$} & Sand and AW at ZIV & 40 & $100 \mathrm{a}$ & $0 \mathrm{a}$ \\
\hline & Sand and $A W$ at $D$ & 40 & $100 \mathrm{a}$ & $0 \mathrm{a}$ \\
\hline & Sand and $A W$ at $\mathrm{J} 1$ & 39 & $100 \mathrm{a}$ & 0 a \\
\hline \multirow[t]{3}{*}{$1 \mathrm{~B}$} & Sand and AW at ZIV & 40 & $100 \mathrm{a}$ & $0 \mathrm{a}$ \\
\hline & Sand and $A W$ at $D$ & 39 & $54 \mathrm{~b}$ & $16 \mathrm{~b}$ \\
\hline & Sand and $A W$ at $\mathrm{J} 1$ & 40 & $35 \mathrm{~b}$ & $41 \mathrm{C}$ \\
\hline \multirow[t]{2}{*}{$1 \mathrm{C}$} & Sand and AW at ZIV & 23 & $74 a$ & - \\
\hline & Sand and AW at D & 34 & $12 \mathrm{~b}$ & - \\
\hline \multirow[t]{4}{*}{$2 \mathrm{~A}$} & Sand and AW at ZIV & 29 & $66 a$ & $21 \mathrm{a}$ \\
\hline & $\mathrm{AW}$ at ZIV & 38 & $24 b$ & $39 a, b$ \\
\hline & Sand at ZIV & 38 & $29 \mathrm{~b}$ & $62 \mathrm{~b}$ \\
\hline & No stimulus at ZIV & 39 & $0 \mathrm{C}$ & $59 \mathrm{~b}$ \\
\hline \multirow[t]{4}{*}{$2 \mathrm{~B}$} & Sand and AW at ZIV & 37 & $95 \mathrm{a}$ & $3 a$ \\
\hline & AW at ZIV & 39 & $79 a, b$ & $3 a$ \\
\hline & Sand at ZIV & 38 & $58 \mathrm{~b}$ & $21 \mathrm{~b}$ \\
\hline & No stimulus at ZIV & 38 & $24 \mathrm{c}$ & $55 \mathrm{c}$ \\
\hline \multirow[t]{4}{*}{$2 \mathrm{C}$} & Sand and AW at ZIV & 39 & $82 \mathrm{a}$ & $3 a$ \\
\hline & AW at ZIV & 39 & $82 \mathrm{a}$ & $10 \mathrm{a}$ \\
\hline & Sand at ZIV & 38 & $55 \mathrm{~b}$ & $8 \mathrm{a}$ \\
\hline & No stimulus at ZIV & 40 & $2 \mathrm{c}$ & $34 \mathrm{~b}$ \\
\hline
\end{tabular}

\section{Burrowing response}

A significantly higher mean percentage of $\mathrm{D}$ was spent burrowed when larvae received sand and adultconditioned water at ZIV than when stimuli were withheld until D (Fig. 2). Thus, postlarvae burrowed more at $\mathrm{D}$ when they had previously received stimuli at ZIV. When stimuli were examined separately, it was evident that each stimulus affected the burrowing activity of decapodids (Fig. 2). Both sand and adult-conditioned water were found to have significant independent effects in Expts 2A, 2B, and $2 \mathrm{C}$ (Fig. 2). In addition to the independent effects of sand and adultconditioned water, the interaction of these stimuli had a significant effect on burrowing activity of decapodids in Expt 2C.

The stage first given sand and adult-conditioned water had a significant determinant effect on the percentage of $J 1$ spent burrowed in both Expts $1 \mathrm{~A}$ and $1 \mathrm{~B}$, though comparisons with the Tukey-Kramer and Tukey compromise post hoc tests (alpha = $0.05)$ revealed one difference between these experiments (Fig. 3). In Expt $1 \mathrm{~A}$ the percentage of $\mathrm{J} 1$ spent burrowed in animals that received sand and adultconditioned water at ZIV was significantly higher than in animals that first received stimuli at $D$ or $\mathrm{J} 1$. However in Expt $1 \mathrm{~B}$, animals that received stimuli at ZIV did not burrow significantly more at $\mathrm{J} 1$ than did animals that received stimuli at $D$.
Student's t-test showed that the duration of ZIV was significantly longer in animals that molted directly from ZIV to D than in those that molted from ZIV to ZV (Table 3). Thus the increase in duration of ZIV in animals that received adult-conditioned water reflects the decreased percentage of animals passing through $\mathrm{ZV}$ in this treatment (Table 2). Data from Expt $1 \mathrm{~A}$ could not be included in Table 3 since all larvae molted directly from ZIV to D.

In most experiments, several animals were malformed at the decapodid stage. In all experiments except $1 \mathrm{~A}$, there were significantly fewer deformed decapodids in animals given both stimuli at ZIV than in those that did not receive a stimulus at ZIV (Table 2). This is similar to the pattern observed in the number of zoeal stages. Animals that had not received stimuli at ZIV were more likely to molt to $\mathrm{ZV}$ and become deformed at the decapodid stage. Most of the animals deformed at D had molted from ZIV to ZV.
Table 3. Callichirus major. Mean durations ( $\pm 95 \% \mathrm{CI}$ ) of the fourth zoeal stage (ZIV) in days for experiments conducted with specimens from the Atlantic coast population of Florida. For all experiments, Student's $t$-test was used to compare the mean duration of ZIV in animals that molted from ZIV to D with those that molted from ZIV to ZV (combining all treatments). Expt $1 \mathrm{~A}$ was not included because almost all animals in that experiment molted from ZIV to D

\begin{tabular}{|c|c|c|c|}
\hline \multirow[t]{2}{*}{ Expt } & \multicolumn{2}{|c|}{ Duration of ZIV } & \multirow{2}{*}{$\mathrm{p}$} \\
\hline & ZIV to $D$ & ZIV to ZV & \\
\hline $1 \mathrm{~B}$ & $3.84( \pm 0.157) n=33$ & $3.46( \pm 0.153) \mathrm{n}=44$ & 0.0006 \\
\hline $1 \mathrm{C}$ & $3.52( \pm 0.233) n=21$ & $3.06( \pm 0.179) n=36$ & 0.002 \\
\hline $2 \mathrm{~A}$ & $3.33( \pm 0.155) \mathrm{n}=39$ & $2.92( \pm 0.064) n=105$ & $<0.0001$ \\
\hline $2 \mathrm{~B}$ & $3.38( \pm 0.132) n=55$ & $2.84( \pm 0.125) n=55$ & $<0.0001$ \\
\hline $2 \mathrm{C}$ & $3.69( \pm 0.152) n=51$ & $3.03( \pm 0.110) n=63$ & $<0.0001$ \\
\hline
\end{tabular}



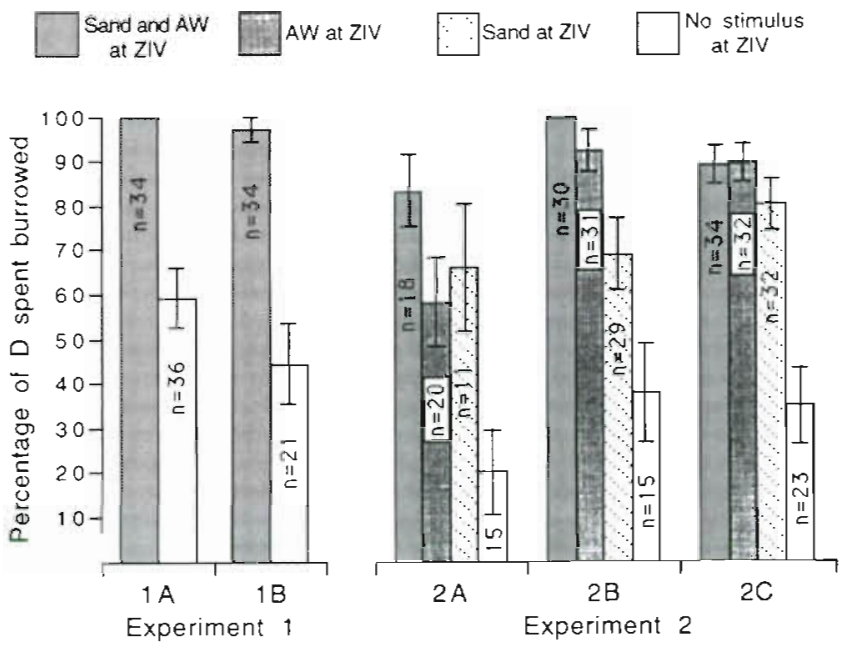

Fig. 2. Callichirus major. Mean percentage $( \pm \mathrm{SE})$ of the decapodid stage (D) spent burrowed in Expts 1 and 2. Animals received sand and adult-conditioned water (AW), AW only, sand only, or no stimulus at the fourth zoeal stage (ZIV), and all animals received sand and $A W$ at $D$. In each experiment $(1 \mathrm{~A}, 1 \mathrm{~B}, 2 \mathrm{~A}, 2 \mathrm{~B}, 2 \mathrm{C})$, the percentage of $D$ spent burrowed was significantly higher (Student's $t$-test, $p=0.0001$ ) in treatments that received sand and AW at ZIV, as opposed to at D (no stimulus at ZIV). A 2-factor ANOVA was used to separate effects of each stimulus in Expts 2A, 2B, and 2C. The effects of sand $\left(2 \mathrm{~A}: F_{1,60}=12.07, \mathrm{p}=0.001 ; 2 \mathrm{~B}: F_{1,101}=9.03, \mathrm{p}=0.0034\right.$; $\left.2 \mathrm{C}: F_{1,117}=16.26, \mathrm{p}=0.0001\right)$ and AW $\left(2 \mathrm{~A}: F_{1,60}=6.98, \mathrm{p}=\right.$ $0.0105 ; 2 \mathrm{~B}: F_{1,101}=44.62, \mathrm{p}=0.0001 ; 2 \mathrm{C}: F_{1,117}=32.53, \mathrm{p}=$ $0.0001)$ were significant in all 3 experiments, while the interaction of stimuli was significant only in Expt $2 \mathrm{C}\left(F_{1,117}=16.28\right.$,

$$
\mathrm{p}=0.0001 \text { ) }
$$

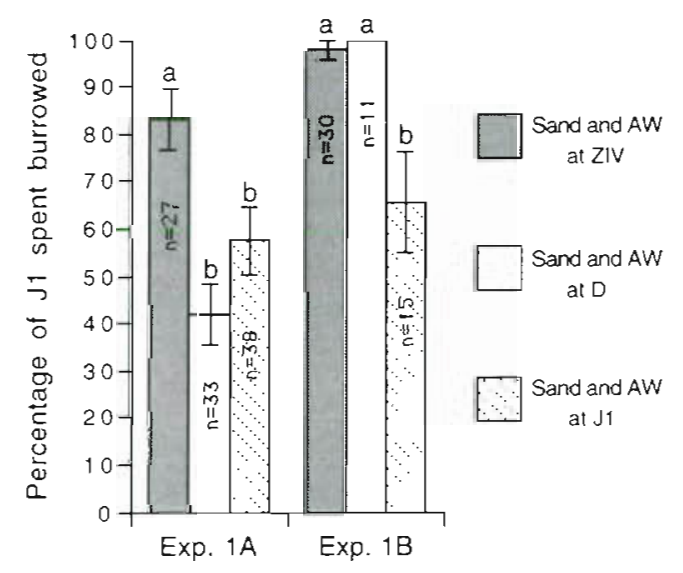

Fig. 3. Callichirus major. Mean percentage of J1 spent burrowed $( \pm \mathrm{SE})$ in Expts $1 \mathrm{~A}$ and $1 \mathrm{~B}$. Animals were first given sand and adult-conditioned water (AW) at the fourth zoeal stage (ZIV), the decapodid stage (D), or the first juvenile stage (J1). An ANOVA revealed that the stage first given stimuli (ZIV, D, or J1) had a significant effect on the percentage of $\mathrm{J} 1$ spent burrowed (1A: $F_{2.95}=9.21, \mathrm{p}=0.0002 ; 1 \mathrm{~B}: F_{2.53}=11.21$, $p=0.0001$ ). Different letters above bars represent treatments within an experiment found to be significantly different with the Tukey-Kramer and Tukey compromise post hoc tests

$$
\text { (alpha }=0.05)
$$

\section{Location of molt}

Significantly more D exuviae were found in the sand (molted from D to J1 while burrowed) for animals that received sand and adult-conditioned water at ZIV than for those that received stimuli at D (Table 4). Fewer molt exuviae were found in the sand for animals that received adult-conditioned water only or sand only at ZIV (Expts 2A, 2B, 2C) than for those that received both stimuli in combination. The percentage of $\mathrm{J} 1$ exuviae (molt from $\mathrm{J} 1$ to $\mathrm{J} 2$ ) found in the sand was also affected by the presence of stimuli at ZIV (Table 5). Animals given sand and adult-conditioned water at ZIV had a significantly higher percentage of J1 exuviae found in the sand than did animals that received stimuli at D or $\mathrm{J} 1$.

\section{DISCUSSION}

Duration of the decapodid stage did not decrease in the presence of stimuli, which suggests that Callichirus major does not delay molting from $\mathrm{D}$ to $\mathrm{J} 1$ in the absence of a cue. This is consistent with findings of other studies on C. major from the east coast of Florida (unpubl. data mentioned in Harvey 1993) and Gulf of

Table 4. Callichirus major. Percentage of decapodid molts (D to J1) found in the sand, as opposed to on top of the sand. In Expt 1, animals received sand and adult-conditioned water (AW) at the fourth zoeal stage (ZIV) or decapodid stage (D). In Expt 2, animals received sand and AW, AW only, sand only, or no stimulus at ZIV and all animals received sand and AW at D. Comparisons were made with Fisher's exact-test and only normal animals (not deformed at D) were included. Different lower case letters represent a significant difference between

\begin{tabular}{|c|c|c|c|c|}
\hline Expt & Treatment & $\begin{array}{r}\text { Number } \\
\text { Found }\end{array}$ & $\begin{array}{l}\text { of D molts } \\
\text { Missing }\end{array}$ & $\begin{array}{l}\% \text { found } \\
\text { in sand }\end{array}$ \\
\hline \multirow[t]{2}{*}{$1 \mathrm{~A}$} & Sand and AW at ZIV & 34 & 0 & $68 \mathrm{a}$ \\
\hline & Sand and AW at D & 36 & 3 & $9 \mathrm{~b}$ \\
\hline \multirow[t]{2}{*}{$1 B$} & Sand and AW at ZIV & 33 & 0 & $88 a$ \\
\hline & Sand and $A W$ at $D$ & 20 & 1 & $5 \mathrm{~b}$ \\
\hline \multirow[t]{4}{*}{$2 \mathrm{~A}$} & Sand and AW at ZIV & 18 & 0 & 56 a \\
\hline & AW at ZIV & 19 & 1 & $16 \mathrm{~b}$ \\
\hline & Sand at ZIV & 11 & 0 & $18 a_{1} b$ \\
\hline & No stimulus at ZIV & 15 & 0 & ob \\
\hline \multirow[t]{4}{*}{$2 \mathrm{~B}$} & Sand and AW at ZIV & 27 & 3 & $81 \mathrm{a}$ \\
\hline & AW at ZIV & 28 & 3 & $14 \mathrm{~b}$ \\
\hline & Sand at ZIV & 26 & 3 & $42 \mathrm{c}$ \\
\hline & No stimulus at ZIV & 8 & 7 & $25 \mathrm{c}, \mathrm{b}$ \\
\hline \multirow[t]{4}{*}{$2 \mathrm{C}$} & Sand and AW at ZIV & 34 & 0 & $71 \mathrm{a}$ \\
\hline & AW at ZIV & 30 & 2 & $23 \mathrm{~b}$ \\
\hline & Sand at ZIV & 29 & 3 & $41 \mathrm{~b}$ \\
\hline & No stimulus at ZIV & 22 & 1 & $0 \mathrm{c}$ \\
\hline
\end{tabular}
treatments within an experiment (alpha $=0.05$ ) 
Table 5. Callichirus major. Percentage of first juvenile molts ( $\mathrm{J} 1$ to J2) found in the sand, as opposed to on top of the sand. Animals received sand and adult-conditioned water (AW) at the fourth zoeal stage (ZIV), decapodid stage (D), or first juvenile stage (J1). Comparisons were made with Fisher's exacttest and only normal animals (not deformed at J1) were included. Different lower case letters represent a significant difference between treatments within an experiment (all tests 2-tailed, alpha $=0.05$ )

\begin{tabular}{|ccccc|}
\hline Expt & $\begin{array}{c}\text { Stage given } \\
\text { sand and AW }\end{array}$ & $\begin{array}{c}\text { Number of J1 molts } \\
\text { Found }\end{array}$ & $\begin{array}{c}\text { M found } \\
\text { in sand }\end{array}$ \\
\hline 1A & ZIV & 24 & 3 & $63 \mathrm{a}$ \\
& D & 26 & 7 & $23 \mathrm{~b}$ \\
$1 \mathrm{~B}$ & J1 & 31 & 8 & $13 \mathrm{~b}$ \\
& ZIV & 28 & 2 & $86 \mathrm{a}$ \\
& D & 10 & 1 & $20 \mathrm{~b}$ \\
& J1 & 13 & 2 & $0 \mathrm{~b}$ \\
\hline
\end{tabular}

Mexico (Strasser \& Felder 1998) but does not mean that decapodids of $C$. major are not receptive to settlement stimuli. It is possible that stimuli received at ZIV promote onset of settlement and that decapodids may make the choice of substrate. Preliminary experiments using sediment combusted to remove organic compounds have shown that decapodids of the Gulf population of $C$. major do receive stimuli from the substrate (Strasser \& Felder pers. obs.). Selective settlement has also been documented for the thalassinidean $\mathrm{NeO}$ trypaea californiensis in which higher densities of postlarvae were found in trays containing mud than epibenthic shell (Feldman et al. 1997). However, the aforementioned study did not determine whether it was the decapodid, or preceding larval stages, that were receptive to substrate qualities.

Although duration of the decapodid stage did not decrease in the presence of stimuli, cues we examined were found to have an effect on development of Callichirus major. The duration of ZIV increased when adult-conditioned water was present. This trend was exactly opposite to that observed in larvae of the Gulf population of $C$. major, which exhibited a decrease in the duration of ZIV in the presence of adult-conditioned water (Strasser \& Felder 1998). Despite these differences, both populations may be accelerating development to $\mathrm{D}$ in the presence of adult-conditioned water. In the Gulf population, animals consistently molted directly from ZIV to D. The presence of ZV was relatively rare and did not depend on the presence or absence of stimuli. In contrast, the presence of $\mathrm{ZV}$ was common during development of the Atlantic population of $C$. major and appeared to depend on the absence of stimuli at ZIV. In larvae from 5 out of 6 parental females, the percentage of animals that molted directly from ZIV to D (bypassing ZV) in- creased significantly when larvae were given adultconditioned water at ZIV (Table 2). By lengthening the duration of ZIV the animal was able to molt directly to $D$, which actually decreased the time it took to reach $D$.

Thus adult-conditioned water accelerates development to the decapodid stage in both populations of Callichirus major, but it does so in different ways. In the Gulf population, which under all conditions seemed to have almost eliminated $Z V$, the duration of ZIV was shortened in the presence of adult-conditioned water. The Atlantic population extended the duration of ZIV in the presence of adult-conditioned water, which appeared to facilitate a direct molt from ZIV to $D$. It should be noted that larvae of one parental female, those used in Expt $1 \mathrm{~A}$ (C. major Atlantic), did not follow the typical pattern. These larvae behaved more like those from the Gulf population in that they did not pass through a $Z V$ in the presence or absence of stimuli. In other experiments with larvae from this same female (those used in Expt 1A), individuals did not alter the number of zoeal stages in response to decreasing salinity. This differs from results obtained with larvae from other parental females, which did change the number of zoeal stages in response to a decrease in salinity (Strasser \& Felder pers. obs.). Thus, larvae from different parental females may differ in their response to environmental cues, which demonstrates the value of repeating each experiment with larvae from another female.

It is not readily evident why the Gulf population of Callichirus major has almost eliminated ZV while this stage occurs commonly in early life history of the Atlantic population, but this may represent some degree of abbreviated development. Marked abbreviation of development in related callianassids of the genus Lepidophthalmus is thought to reflect an adaptation for retention of these oligohaline species in disjunct coastal estuaries (Nates et al. 1997). The Atlantic population of $C$. major inhabits exposed, intertidal, high energy, quartzite sand beaches, which are readily available along the southeastern U. S. Atlantic coast. In the Gulf of Mexico, similar habitats are instead more commonly dominated by the congener $C$. islagrande. The Gulf population of $C$. major inhabits primarily lower intertidal to shallow subtidal waters along low energy beaches, including those of channels and bayward sides of barrier islands where quartzite sands are less cleanly sorted and waters may be euryhaline. As such substrates are associated with estuary mouths in the northern Gulf of Mexico and are often disjunct in distribution, decreased larval duration in Gulf populations of C. major may favor retention in these restricted habitats. In the course of our field collections to date, ZIII and ZIV larvae have been found in close proximity to such adult habitats (Strasser \& Felder pers. obs.) 
Salinity has been shown to affect the number of developmental stages in other decapod crustaceans (Robertson 1968, Anger 1991). Since the 2 populations of Callichirus major compared in this study appear to thrive at different salinity optima, experiments were conducted at salinities that would closely approximate those of the adult habitats (35 ppt for the Atlantic population, and $25 \mathrm{ppt}$ for the Gulf population). While salinity may have an effect on the presence of $\mathrm{ZV}$ in the Atlantic population, the Gulf population was not affected in the same way. The presence of $\mathrm{ZV}$ was rare in larvae from the Gulf population when reared at either $25 \mathrm{ppt}$ or $35 \mathrm{ppt}$ salinity (Strasser \& Felder pers, obs.).

Morphology of ZV was variable among individuals from the same parental female but always appeared to represent some grade between ZIV and D. ZV was frequently observed in development of the Gulf of Mexico congener Callichirus islagrande. In that species, ZV closely resembled ZIV with minor advances in development such as setae on the pleopods (Strasser \& Felder pers. obs.). Although rarely observed, ZV in the Gulf population of $C$. major was also close morphologically to ZIV. In contrast, ZV in the Atlantic population was typically most similar to $D$ but had the rostrum, telson, and dorsal abdominal spines of ZIV. In the Atlantic population of $C$. major, animals that molted to $\mathrm{ZV}$ often were deformed at $\mathrm{D}$. While the degree of deformity varied between individuals, even minor morphological changes could have inhibited burrowing, so analysis of burrowing activity did not include deformed individuals. Had these animals been included in analyses, the differences observed in burrowing response would have been only more pronounced between treatments.

$\mathrm{ZV}$ larvae could be identified by their swimming behavior, which resembled that of ZIV. There was a profound behavioral change between the zoeal stages and the decapodid. In most respects this made the molt to $\mathrm{D}$ more dramatic than the molt to $\mathrm{J} 1$, the latter of which is sometimes mistaken to be the main metamorphic molt (Felder et al, 1985). ZIV larvae usually swam backwards and frequently jerked backwards while decapodids exhibited forward swimming. Decapodids made backward jerking motions, but did so infrequently and usually in response to a threat (such as the tip of a pipette). Like many other decapod crustaceans, adult Callichirus retain the backward escape response.

The fourth zoeal stage was important not only in modulating development but also in the settlement process. Animals that received sand and adult-conditioned water at ZIV were more likely to burrow as decapodids than were animals that received stimuli at a later stage. This pattern was observed also when the location of molts was examined. Significantly more D exuviae were found in the sand when animals received sand and adult-conditioned water at ZIV, than when stimuli were given at $D$. This trend was similar to that observed in larvae of Callichirus major from the Gulf of Mexico (Strasser \& Felder 1998). Thus in both populations, settlement was delayed or inhibited when ZIV larvae were not given sand and adult-conditioned water.

Location of the exuvium represents the location of the animal at the time of molt. If the exuvium was found in the sand, it was likely that the animal was burrowed when it molted. Exuviae found in sand were typically covered with sand grains and tattered, while those found on the sand surface were usually clean and intact. Animals that received adult-conditioned water only at ZIV (Atlantic population) often burrowed as decapodids but molted to $\mathrm{J} 1$ on the surface of the sand. This may suggest that these animals had not settled permanently. Like the Gulf population, perhaps the Atlantic population requires the presence of sand at ZIV to settle at D. ZIV larvae made contact with the sand, and produced depressions in the sand along edges of the container.

Another difference between populations of $\mathrm{Cal}$ lichirus major is evident when stimuli are examined separately. In the Gulf population, sand had a significant effect on the burrowing activity of decapodids. The presence of sand at ZIV significantly increased the percentage of $D$ spent burrowed, while adultconditioned water decreased this percentage. In addition, sand at ZIV appeared to be equivalent to the combination of stimuli in terms of burrowing activity and location of exuviae (Strasser \& Felder 1998). In the Atlantic population both adult-conditioned water and sand significantly increased both burrowing activity at $\mathrm{D}$ and the percentage of exuviae found in the sand. However, neither adult-conditioned water nor sand alone were equivalent in effect to the combination of stimuli. A similar pattern was observed in the grapsid Chasmagnathus granulata (Dana). A combination of natural sediment and adult-conditioned water accelerated molting to $\mathrm{J} 1$ more than did either stimulus offered alone (Gebauer et al. 1998).

The Gulf population of Callichirus major responded to both adult-conditioned water and sand as settlement stimuli. While adult-conditioned water decreased the duration of ZIV, it did not appear to affect settlement in this population (Strasser \& Felder 1998). In contrast, adult-conditioned water affected both the time to metamorphosis (to D) and the settlement of postlarvae in the Atlantic population. Animals from this population that did not receive an adult-related waterborne cue at ZIV were more likely to molt to ZV and become deformed decapodids. While sand alone was sufficient 
to trigger settlement in the Gulf population, the Atlantic population of $C$. major appeared to require the presence of both stimuli at ZIV. These data document differences that corroborate other research findings on genetic divergence (Staton \& Felder 1995), differences in habitats and distributions of adults (Felder \& Griffis 1994), and distinctions in morphology of larvae (Strasser \& Felder 1999) for these 2 populations.

Acknowledgements. We thank R. P. Bourgeois, K. Hill, J. G. MaKinster, R. B. Manning, S. F. Nates, and Kurt M. Strasser who assisted with field collections and M. E. Rice, Director of the Smithsonian Marine Station-Link Port, Florida, who facilitated access to station facilities used during analytical phases of this project. We also thank R. T. Bauer, R. G. Jaeger, R. Lemaitre, and G. M. Watson for comments on the manuscript, as well as R. B. Manning who gave advice on collecting sites and facilitated funding. Direct support for this study was provided to K.M.S. by a doctoral fellowship from The University of Southwestern Louisiana, a graduate student research grant from the LUMCON (Louisiana Universities Marine Consortium) Foundation, and a summer research award from the Smithsonian Marine Station. Additional support for field and lab activities was provided to D.L.F. under Louisiana Sea Grant College Program Grant R/CFB-21, U.S. Fish and Wildlife Service Cooperative Agreement 14-16-0009-89-96 (Task Order No. 6), U.S. Department of Energy grant DE-FG0297ER12220, and several small project grants from the Smithsonian Marine Station. Views expressed herein are those of the authors, and do not necessarily reflect views of supporting government agencies or subagencies mentioned above. This is contribution No. 468 for the Smithsonian Marine Station and contribution No. 63 for the USL Laboratory for Crustacean Research.

\section{LITERATURE CITED}

Anger $\mathrm{K}$ (1991) Effects of temperature and salinity on the larval development of the Chinese mitten crab Eriocheir sinensis (Decapoda: Grapsidae). Mar Ecol Prog Ser 72:103-110

Christy JH (1989) Rapid development of the megalopa of the fiddler crab Uca pugilator reared over sediment: implications for models of larval recruitment. Mar Ecol Prog Ser 57:259-265

Cobb SJ (1968) Delay of moult by the larvae of Homarus americanus. J Fish Res Board Can 25:2251-2253

Felder DL (1978) Osmotic and ionic regulation in several western Atlantic Callianassidae (Crustacea, Decapoda, Thalassinidea). Biol Bull 154:409-429

Felder DL, Griffis RB (1994) Dominant infaunal communities at risk in shoreline habitats: burrowing thalassinid Crustacea. OCS Study \# MMS 94-0007. US Dept of the Interior, Minerals Mgmt. Service, Gulf of Mexico OCS Regional Office, New Orleans, LA 87

Felder DL, Martin JW, Goy JW (1985) Patterns in early postlarval development of decapods. In: Schram FR (ed) Crustacean Issues 2. San Diego Natural History Museum, p $163-226$

Feldman KL, Armstrong DA, Eggleston DB, Dumbauld BR (1997) Effects of substrate selection and post-settlement

Editorial responsibility: Kenneth Heck (Contributing Editor), Dauphin Island, Alabama, USA survival on recruitment success of the thalassinidean shrimp Neotrypaea californiensis to intertidal shell and mud habitats. Mar Ecol Prog Ser 150:121-136

Gebauer P. Walter I, Anger K (1998) Effects of substratum and conspecific adults on the metamorphosis of Chasmagnathus granulata (Dana) (Decapoda: Grapsidae) megalopae. J Exp Mar Biol Ecol 223:185-198

Harms J (1992) Larval development and delayed metamor phosis in the hermit crab Clibanarius erythropus (Latreille) (Crustacea: Diogenidae). J Exp Mar Biol Ecol 156:151-160

Harvey AW (1992a) Costs and benefits of delayed metamorphosis in the Australian hermit crab Clibanarius longitarsus. Am Zool 32:114A

Harvey AW (1992b) Abbreviated larval development in the Australian terrestrial hermit crab Coenobita variabilis McCulloch (Anomura: Coenobitidae). J Crust Biol 12:196-209

Harvey AW (1993) Larval settlement and metamorphosis in the sand crab Emerita talpoida (Crustacea: Decapoda: Anomura). Mar Biol 117:575-581

Harvey AW (1996) Delayed metamorphosis in Florida hermit crabs: multiple cues and constraints (Crustacea: Decapoda: Paguridae and Diogenidae). Mar Ecol Prog Ser 141: $27-36$

Harvey AW, Colasurdo EA (1993) Effects of shell and food availability on metamorphosis in the hermit crabs Pagurus hirsutiusculus (Dana) and Pagurus granosimanus (Stimpson). J Exp Mar Biol Ecol 165:237-249

Jensen GC (1989) Gregarious settlement by megalopae of the porcelain crabs Petrolisthes cinctipes (Randall) and $P$. eriomerus Stimpson. J Exp Mar Biol Ecol 131:223-231

Jensen GC (1991) Competency, settling behavior, and postsettlement aggregation by porcelain crab megalopae (Anomura: Porcellanidae). J Exp Mar Biol Ecol 153:49-61

Knight-Jones EW (1953) Laboratory experiments on gregariousness during setting in Balanus balanoides and other barnacles. J Exp Biol 30:584-598

Nates SF, Felder DL, Lemaitre R (1997) Comparative larval development in two species of the burrowing ghost shrimp genus Lepidophthalmus (Decapoda: Callianassidae). J Crust Biol 17:497-519

O'Connor NJ, Judge ML (1997) Flexibility in timing of molting of fiddler crab megalopae: evidence from in situ manipulation of cues. Mar Ecol Prog Ser 146:55-60

Raimondi PT (1988) Settlement cues and determination of the vertical limit of an intertidal barnacle. Ecology 69:400-407

Robertson PB (1968) The complete larval development of the sand lobster, Scyllarus americanus (Smith), (Decapoda, Scyllaridae) in the laboratory, with notes on larvae from the plankton. Bull Mar Sci 18:294-342

Staton JL, Felder DL (1995) Genetic variation in populations of the ghost shrimp genus Callichirus (Crustacea: Decapoda: Thalassinoidea) in the western Atlantic and Gulf of Mexico. Bull Mar Sci 56:523-536

Strasser KM, Felder DL (1998) Settlement cues in successive developmental stages of the ghost shrimp Callichirus major and C. islagrande (Crustacea: Decapoda: Thalassinidea). Mar Biol 132:599-610

Strasser KM, Felder DL (1999) Larval development of two populations of the ghost shrimp Callichirus major (Decapoda: Thalassinidea). $J$ Crust Biol (in press)

Weber JC, Epifanio CE (1996) Response of mud crab (Panopeus herbstii) megalopae to cues from adult habitat. Mar Biol 126:655-661

Submitted: June 8, 1998; Accepted: January 25, 1999

Proofs received from author(s): June 16, 1999 